\title{
Evaluating the Policy Claims of Migration in Nepal
}

\author{
Asmod Karki \\ Yenching Scholar, Peking University, China \\ akarki@pku.edu.cn
}

\begin{abstract}
The Government of Nepal published the landmark Compact Rural Settlements Policy (CRSP) in 2013. The policy paper argued for clustering settlements in rural Nepal in order to improve quality of life for people. One of the main arguments of this paper is that rural out-migration happens due to lack of services. This paper analyzes the relationship between migration and availability of services in Nepal. The results demonstrate that the relationship among migration decision, availability of health and education services is statistically insignificant. In other words, the claims of the CRSP paper needs to be reevaluated and a comprehensive cost-benefit analysis of resettlements should be conducted before government led clustered settlements are built in the country.
\end{abstract}

Keywords: Migration, Resettlements, Compact Rural Settlement Policy, Access to Facilities

\section{Introduction}

The Compact Rural Settlements Policy (CRSP) 2013 assumes provision of basic services crucial to economic development. This claim is not new in the arena of development. First, the argument goes, the access to basic services will help people improve their life standard (NPC, 2013). The second argument is more implicit, which assumes that availability of these services will help enhance human capabilities (Sen, 2005). The rationale behind the second argument is that the capable individuals will then propel forward the economic development.

This paper will closely examine the first argument in the context of a policy brief related to resettlement in Nepal. The CRSP argues that poor people in rural Nepal migrate from places with low availability of basic services such as healthcare and education to those places with high availability of services. In other words, the policy brief is making a claim that rural outmigration in Nepal is primarily propelled by lack of access to basic services. Thus, the rationale behind setting up clustered settlements as per the policy brief is that people in such settlements will have access to basic services, which will help them improve their lifestyle (NPC, 2013).

The need to examine these arguments arises from the fact that the policy brief does not provide adequate explanation for their assumptions related to migration in rural Nepal. Moreover, there are very few studies that look at the migration pattern in different regions of Nepal. Gurung et al. (1983) studied the regional migration in Nepal but it was well before the rapid urbanization and outmigration began in Nepal.

In 1990s and 2000s, Nepal saw massive increase in out-migration (Seddon et al., 2002) and the population in urban centers rose dramatically (Thapa and Murayama, 2010). The recent studies in the area have mostly focused in Chitwan, which lies in the Terai region of Nepal (Shrestha and Bhandari, 2007; Bohra et al., 2011). However, results from a town in Terai cannot be used to generalize findings about Nepal because Terai region is geographically different than the mountains and hills. Terai also has comparatively greater percentage of population and numerous town centers than the other two regions. These factors might affect the migration pattern in Terai differently than in the hills and mountains.

While the assumptions in the CRSP might work for a country or a region that is largely homogenous in terms of ethnicity and race, provision of services by the state, and income distribution of people in different regions of 
the country, the assumptions need to be tested in a country like Nepal, that has diverse quality of services and socio-cultural contexts. This is because here we are discussing variations in not just one of the variables, i.e. geography, that was supposed to remain constant in the assumption but in a wide range of variables, such as level of infrastructures and presence of a town center nearby, that often interact with each other factors to produce complex decision-making frameworks.

The diversity in population, with more than 120 ethnic groups (CBS, 2012), means that there are different socio-cultural contexts in which people live. With our socio-cultural contexts influencing our decisions, we can infer that the greater the diversity in this arena, the greater the difference in frameworks under which people make decisions. Similarly, the diversity in geography might also influence the migration

patterns. The variation in the administrative region also adds complexity to the migration dynamics.

\section{Literature review}

There have been mixed findings regarding the relationship between migration and the availability of resources. Some studies show that rural out-migration happens primarily due to scarcity. People migrate from places with scarce resources to places with ample resources. Bilsborrow (1998) argues that the rural out-migration can in part be attributed to the "official neglect of rural economic conditions, despite rhetorical commitments to rural development." Following the same line of argument, Ezra and Kiros (2001) extend the argument to environmental resources. In a study about the rural out-migration in Ethiopia, they found that "impoverished rural communities" have minimal mobility for schooling purposes, and vulnerability to food crisis is positively associated with rural out-migration.

In other words, they are claiming that people migrate from situation of scarcity of resources to places with ample resources as a riskdiversification strategy for households. This is consistent with the new economics of migration theory. This theory states that households and sometimes even communities use migration as a risk-diversification strategy. They use migration to mitigate risks and maximize income (Massey, 1999). Similarly, in a study in Chitwan valley in
Nepal Bohra et al. (2011) found that movements within the vicinity is predicted by the time taken to collect firewood.

However, some studies have shown contrasting finding to the above studies. For instance, White and Lindstrom (2005) found that social processes are strong predictors of rural out-migration in least developed countries. They argue that the explanation of rural out-migration related to the "geographical differences of economic opportunities and resources" fails to explain the origin of the migration pattern in some places and not others. Similarly, Gray (2009) extends the argument to the availability of environmental resources. His study of smallholder farmers in rural Ecuadorian Andres shows that years of higher migration in the region is correlated with years of higher rainfall. Similarly, Nawrotzki et al. (2013) present similar finding in their study of migration patterns in rural Mexico. They found that households with more resources have more migration rates than their neighbors who have low resources. The resources in question was the crop patterns.

\section{Hypothesis}

As Nepal is also a least developed country with a significant percentage of the population living in rural areas, the migration pattern can be explained either by scarcity of resources, as claimed in the Compact Rural Settlements (CRS) policy brief or by relative abundance of resources in the place of origin. Had Nepal been largely homogenous in its geographical, ethnic and economic makeup it would have been relatively straightforward to make assumptions. In general, we should expect the individuals to migrate to places with more access to resources, which is the assumption made in the CRSP.

\section{Method}

\section{Description of the Sample:}

I used the National Living Standard Survey (NLSS) III for the purpose of analysis. The NLSS surveys are administered by the Central Bureau of Statistics in Nepal with the support of the World Bank. The first NLSS was administered in 1995/6. Nearly a decade after the first survey, NLSS II was administered in 2003/4. NLSS III, which is used in this paper, was administered in 2010/11.

There are three units of analysis in NLSS 
III. Data is collected at individual, household, and community level. The NLSS III enumerated 5988 households from 499 Primary Sampling Units (PSUs). In addition, it also tracked 1032 households that were enumerated in NLSS I and NLSS II. Thus, in total 7020 households were enumerated.

The PSUs in NLSS III are classified into fourteen strata, and both the rural and urban areas have their own datasets. I used the datasets of rural Nepal because the claims of the CRS pertain to rural parts of the country. In NLSS III, rural Nepal is classified into eleven strata that considers both the geographical and administrative differences. The regions in the Terai and in the Hills are classified based on the development regions, whereas the whole of the Mountain region is treated as one strata. The Hilly and Terai PSUs in five development regions constitute the remaining ten strata. The eleven strata used in the analysis are: Mountain, Eastern Hill, Central Hill, Western Hill, Mid-Western Hill, Far-Western Hill, Eastern Terai, Central Terai, Western Terai, Mid-Western Terai and FarWestern Terai.

\section{Inclusion of the Regions:}

In order to take the various diversities into account, I analyze the influence of the five development regions and the three ecological regions separately. Before we proceed, it is worthwhile to briefly discuss about the different regions in Nepal. Nepal is ecologically divided into three different regions: Mountain, Hill and Terai. The basis of division is the altitude of different regions. The Mountain region lies to the north of the country and is dominated by the presence of tall snow peaked mountains. The Terai region lies to the south, extending from the east to the west. The Terai is relatively flat compared to the Mountain and the Hill regions. It also has some of the most fertile land in the country and is called the bread basket of Nepal. The Hilly region lies between the Mountain and the Terai.

Administratively, the country is divided into 75 districts, 14 zones and 5 development regions. Each district has multiple Village Development Committees (VDCs) or Municipalities depending on the population and facilities present in the area. Several districts are aggregated to form a zone and several zones are combined to form a development region. Each development region has all the three ecological regions present in it. The five development regions in the country are: Eastern, Central, Western, Mid-Western, and Far-Western.

One of the reasons for including the development regions is that there is uneven distribution of resources and services in different regions of the country. The regions around central Nepal, where Kathmandu is located, has been historically endowed with higher concentration of development activities. The regions in the western part, especially the mid-west and farwest regions, have not seen the same level of investment in basic resources from the state as regions around Kathmandu have.

As for the ecological classification, the NLSS III does not further classify the mountain districts into different regions. There are also no major town centers in the mountain region that has a population of more than 20,000 (Aparicio and Muzzini, 2013). As development of a town center requires a hub of services including access to roads and a functioning market place large enough to sustain the population residing within close proximity, absence of a large town center in this region might suggest that this region in Nepal remains either unattractive, or in the least unfeasible, for clustered settlements. Thus, inclusion of this region even without further dividing into sub-regions will likely yield us insight into the behaviors of people living in terrains with challenging geography. 
Description of the Variables:

\begin{tabular}{|c|c|c|c|c|c|c|}
\hline Number & Source & Variables & Description & Values & Mean & $\begin{array}{l}\text { Standard } \\
\text { Deviation }\end{array}$ \\
\hline 1 & $\mathrm{HH}$ & Migration & $\begin{array}{l}\text { Has the } \\
\text { individual } \\
\text { migrated } \\
\text { before? }\end{array}$ & $\begin{array}{l}0 \text { - No } \\
1-\text { Yes }\end{array}$ & NA & NA \\
\hline 2 & $\mathrm{HH}$ & Time_HealtPost & $\begin{array}{l}\text { Time taken in } \\
\text { minutes to walk } \\
\text { to the nearest } \\
\text { sub-health/ } \\
\text { health post }\end{array}$ & $\begin{array}{l}\operatorname{Min}=0 \\
\operatorname{Max}=840\end{array}$ & 52.37 & 50.67 \\
\hline 3 & $\mathrm{HH}$ & Time_School & $\begin{array}{l}\text { Time taken in } \\
\text { minutes to walk } \\
\text { to the nearest } \\
\text { primary school }\end{array}$ & $\begin{array}{l}\operatorname{Min}=0 \\
\operatorname{Max}=840\end{array}$ & 21.06 & 41.48 \\
\hline 4 & $\mathrm{HH}$ & $\begin{array}{l}\text { Food_ } \\
\text { Consumption }\end{array}$ & $\begin{array}{l}\text { Annual nominal } \\
\text { amount in } 1000 \\
\text { Rs. Spent by an } \\
\text { individual for } \\
\text { food. }\end{array}$ & $\begin{array}{l}\operatorname{Min}=0 \\
\operatorname{Max}=840\end{array}$ & 16.89 & 5.85 \\
\hline 5 & $\mathrm{HH}$ & Age & $\begin{array}{l}\text { Age of the } \\
\text { individual }\end{array}$ & $\begin{array}{l}\operatorname{Min}=5 \\
\operatorname{Max}=99\end{array}$ & 28.19 & 19.53 \\
\hline 6 & $\mathrm{HH}$ & Sex & $\begin{array}{l}\text { Sex of the } \\
\text { individual }\end{array}$ & $\begin{array}{l}0 \text { - Female } \\
1 \text { - Male }\end{array}$ & NA & NA \\
\hline 7 & $\mathrm{HH}_{-}$ & HH_Size & $\begin{array}{l}\text { Size of the } \\
\text { individual }\end{array}$ & $\begin{array}{l}\operatorname{Min}=0 \\
\operatorname{Max}=99\end{array}$ & 6.15 & 2.60 \\
\hline 8 & $\mathrm{HH}$ & Geography & $\begin{array}{l}\text { Different } \\
\text { geographical } \\
\text { regions }\end{array}$ & NA & NA & NA \\
\hline 9 & $\mathrm{HH}$ & $\begin{array}{l}\text { Perception } \\
\text { Health Facilities }\end{array}$ & $\begin{array}{l}\text { How does the } \\
\text { household } \\
\text { perceive the } \\
\text { available health } \\
\text { facilities? }\end{array}$ & $\begin{array}{l}0 \text { - Less than } \\
\text { adequate } \\
1 \text { - Adequate } \\
\text { or more than } \\
\text { adequate }\end{array}$ & NA & NA \\
\hline 10 & $\mathrm{HH}$ & $\begin{array}{l}\text { Perception } \\
\text { Education } \\
\text { Facilities }\end{array}$ & $\begin{array}{l}\text { How does the } \\
\text { household } \\
\text { perceived } \\
\text { available } \\
\text { education } \\
\text { facilities/ }\end{array}$ & $\begin{array}{l}0 \text { - Less than } \\
\text { adequate } \\
1 \text { - Adequate } \\
\text { or more than } \\
\text { adequate }\end{array}$ & NA & NA \\
\hline 11 & $\mathrm{HH}$ & Recentness & $\begin{array}{l}\text { Has the } \\
\text { individual } \\
\text { lived outside of } \\
\text { two months or } \\
\text { more? }\end{array}$ & $\begin{array}{l}0 \text { - No and once } \\
1 \text { - More than } \\
\text { once }\end{array}$ & NA & NA \\
\hline
\end{tabular}




\begin{tabular}{|c|c|c|c|c|c|c|}
\hline 12 & $\begin{array}{l}\mathrm{HH}-2 \\
\text { and } 9\end{array}$ & $\begin{array}{l}\text { Interaction_ } \\
\text { Health }\end{array}$ & $\begin{array}{l}\text { Is an individual } \\
\text { who has } \\
\text { migrated for } \\
\text { two months } \\
\text { or more in the } \\
\text { past five years } \\
\text { more likely to } \\
\text { live away from a } \\
\text { health facility? }\end{array}$ & $\begin{array}{l}\operatorname{Min}=0 \\
\operatorname{Max}=1680\end{array}$ & 101.45 & 100.07 \\
\hline 13 & $\begin{array}{l}\mathrm{HH}-3 \\
\text { and } 10\end{array}$ & $\begin{array}{l}\text { Health } \\
\text { Education }\end{array}$ & $\begin{array}{l}\text { Is an individual } \\
\text { who has } \\
\text { migrated for } \\
\text { two months } \\
\text { or more in the } \\
\text { past five years } \\
\text { more likely to } \\
\text { live away from } \\
\text { an educational } \\
\text { facility? }\end{array}$ & $\begin{array}{l}\operatorname{Min}=0 \\
\operatorname{Max}=2890\end{array}$ & 40.65 & 80.60 \\
\hline 14 & $\mathrm{HH}$ & wt_ind & $\begin{array}{l}\text { Individual } \\
\text { Weights }\end{array}$ & $\begin{array}{l}\operatorname{Min}=280.33 \\
\operatorname{Max}=29247.31\end{array}$ & 7023.32 & 3395.82 \\
\hline
\end{tabular}

\section{Analytic Approach:}

I used the probit regression method to analyze the data. The model can be represented as:

$$
\operatorname{Pr}(\mathrm{Y})=\mathrm{aU}+\mathrm{bV}+\mathrm{cW}+\mathrm{dX}+\mathrm{Z}
$$

The dependent variable of interest is the probability of an individual migrating to a destination. Here Y represents whether or not an individual has migrated. Our main independent variable of interest is the time taken to walk to the facilities. We are interested in two facilities, i.e. a health post and a primary school. In the equation they are represented by $\mathrm{U}$ and $\mathrm{V}$, respectively.

Before proceeding, I analyzed if the two main independent variables are collinear. It might be the case that the time taken to walk to the educational facility might impact the time taken to reach the nearest health post. A collinearity check of the access to two variables showed that they have low correlation, around 0.19, which makes it safe to include both in the regression.

Several factors might influence the decision of people to move to a certain place in rural areas. We included these factors as controls, which is represented by $\mathrm{W}$ in the equation. For instance, people's socio-economic status might influence both the distance they live from the health post and the migration decision. Thus, it is important to control people's socio-economic status. I choose the annual nominal amount spent on food by an individual as a proxy of people's socio-economic status. The reason behind selecting people's consumption comes with the assumption that people's socio-economic status correlates positively with their spending on food.

Similarly, age is another control factor included in the equation. Those who are of working age might be more likely to migrate than people located at the extremes of the age spectrum, i.e. children and old people. I hypothesize that people aged $15-30$ should migrate more than the younger population but less the older population. This is because age might determine how people access basic services. For instance, young people in general might access the services more than old people and children because accessing services requires travel, which is both physically and mentally demanding especially when people have to travel a long distance. Similarly, young people also might migrate more than the children because children usually stay with their parents at home. However, I hypothesize them to migrate less than the older population because migration to rural Nepal usually means relocating to places where the market economy is under-developed. As a result, people who would migrate to these places would want to be familiar with the agriculture and farming technique. The 
assumption I am making here is that old people have more experience and knowledge about agriculture in general than younger people living in rural areas.

People's gender might also influence the migration pattern and access to services. Women in Nepal generally move to their husband's house after marriage. Moreover, women sometimes have different needs than men, especially regarding maternal health (Sharma et al. 2007). Thus, they might use the services differently than men in rural areas. Vast literature exists regarding relationship between access to education and gender (Fentiman et al. 1999; Llyod et al. 2005). Thus, I hypothesize that being a male is positively associated with migration than being a female.

Another control that is included in the model is the household size. People with small family size might have different flexibility regarding migration decisions than people with large family size. Similarly, family size might also determine the type and quantity of different resources available to a person, including access to basic services. As rural Nepal is mostly agricultural, households would need family members at home to do farm related activities. Thus, I hypothesize that individuals from larger households are more likely to migrate than those from smaller households.

As discussed earlier, the unequal level of development in different regions might affect both the migration decisions of individuals and the time required to travel to the nearest facilities such as a health post and a primary school. In the analysis, we compare migration of individuals in different regions of the country compared to those who live in the mountain region. This is because the mountain region has a low percentage, i.e. 6.73, of total population as compared to the Terai and the Hills, which have 50.27 and 43 percent of the total population respectively (CBS, 2012). In general, we should expect people to move less into the mountainous regions and more into the
Terai regions because the rugged geography of the mountain region might make it difficult for individuals to get access to basic services.

Another control included in the model is the recentness of migration. It is because people who have migrated for two months or more in the last five years might demonstrate different patterns than those who have not migrated before. Similarly, the recentness of the migration might also influence whether people are likely to live near the facilities or not. Thus, I hypothesize that people who have left their home for more than two months or more in the last five years should be more likely to migrate.

To examine the impact of prior migration and the time taken to access facilities, I included interaction terms as a control. There are two interaction terms in the equation. One for the interaction between access to a health facility and recentness of migration, and the other for access to a primary school and recentness of migration. The interaction terms are denoted by $\mathrm{W}$ in the equation.

Perception is another important factor to consider because people might perceive the availability of same facilities differently depending on their needs and various other factors, which might affect the migration decisions. Moreover, distance from facilities might also influence the perception people have towards usage of that facility. I hypothesize that the more unsatisfactory this perception is, the more people are likely to migrate. The coefficients, a, b, c and d are the marginal effects at the mean of the independent variables. I used marginal effects because the coefficient obtained from the probit regression only gives us an idea about the change in z-score. Marginal effects on the other hand, describes us the percentage change in the probability of the dependent variable keeping the control variables fixed at the mean. 
Results:

\begin{tabular}{|c|c|c|c|}
\hline \multirow[t]{2}{*}{ VARIABLES } & (1) & $(2)$ & (3) \\
\hline & Migration & Migration & Migration \\
\hline Time_HealthPost & $-0.000590^{* * * * *}$ & 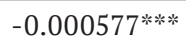 & 0.000390 \\
\hline \multirow[t]{2}{*}{ Time_School } & $(0.000108)$ & $(8.92 \mathrm{e}-05)$ & $(0.000628)$ \\
\hline & -0.000400 & -0.000354 & -0.00233 \\
\hline \multirow[t]{2}{*}{ Food_Consumption } & $(0.000302)$ & $(0.000270)$ & $(0.00202)$ \\
\hline & $0.00468^{* * * * *}$ & $0.00237^{* * * * *}$ & $0.00236 * * *$ \\
\hline \multirow[t]{2}{*}{ Age(15-30) } & $(0.000553)$ & $(0.000460)$ & $(0.000459)$ \\
\hline & & $0.275^{* * * * *}$ & $0.269^{* * * *}$ \\
\hline \multirow[t]{2}{*}{ Age (30+) } & & $(0.00935)$ & $(0.00914)$ \\
\hline & & $0.412^{* * * *}$ & $0.407^{* * * * * *}$ \\
\hline \multirow[t]{2}{*}{ Sex } & & $(0.00837)$ & $(0.00819)$ \\
\hline & & $-0.307^{* * * * *}$ & $-0.308^{* * * *}$ \\
\hline \multirow[t]{2}{*}{ HH_Size } & & $(0.00742)$ & $(0.00725)$ \\
\hline & & $-0.00255^{*}$ & $-0.00578^{* * * * * *}$ \\
\hline \multirow[t]{2}{*}{ Recentness } & & $(0.00148)$ & $(0.00143)$ \\
\hline & & -0.0136 & -0.0296 \\
\hline \multirow[t]{2}{*}{ Terai } & & $(0.0144)$ & $(0.0248)$ \\
\hline & & & $0.122^{* * * * *}$ \\
\hline \multirow[t]{2}{*}{ Eastern } & & & $(0.00837)$ \\
\hline & & & $0.0818 * * * *$ \\
\hline \multirow[t]{2}{*}{ Central } & & & $(0.0151)$ \\
\hline & & & $0.0585^{* * * *}$ \\
\hline \multirow[t]{2}{*}{ Western } & & & $(0.0149)$ \\
\hline & & & $0.0756^{* * * *}$ \\
\hline \multirow[t]{2}{*}{ Mid-Western } & & & $(0.0151)$ \\
\hline & & & -0.00702 \\
\hline \multirow[t]{2}{*}{ Far-Western } & & & $(0.0155)$ \\
\hline & & & $0.108^{* * * * *}$ \\
\hline \multirow[t]{2}{*}{ Perception_Health } & & & $(0.0175)$ \\
\hline & & & 0.00492 \\
\hline \multirow[t]{2}{*}{ Perception_Education } & & & $(0.0103)$ \\
\hline & & & -0.00516 \\
\hline \multirow[t]{2}{*}{ Interaction_Health } & & & $(0.0103)$ \\
\hline & & & -0.000218 \\
\hline \multirow[t]{3}{*}{ Interaction_Education } & & & $(0.000320)$ \\
\hline & & & 0.00109 \\
\hline & & & $(0.00102)$ \\
\hline Observations & 11,358 & 11,358 & 11,358 \\
\hline
\end{tabular}

Table 1: Standard errors in parentheses. ${ }^{* * * *} p<0.01,{ }^{* *} p<0.05,{ }^{*} p<0.1$. The interaction term relates Time_Health post with the Frequency. 
The main hypothesis being tested in this analysis is whether or not access to basic services is related to people's migration decision. The results show that access to a health post is negatively correlated with people's decision to migrate when the geographical and administrative differences are not taken into account. A minute increase in the time taken to travel to the nearest health post is associated with 0.03 percentage point increase in the probability of migration, measured at 52.57 minutes. The result is statistically significant at $1 \%$ level. However, the result is not statistically significant when we control the influence of geographical and administrative regions in the country. Similarly, the relationship between people's migration decision and the access to a primary school is also statistically insignificant in the second case.

We found that people's socio-economic status is positively correlated with their decision to migrate. A thousand rupees increase in the consumption of food is associated with 0.2 percentage point increase in the probability of moving into a place, measured at 16.89 thousand rupees. The result is significant at $1 \%$ level.

Young people are more likely to migrate than children. People belonging to the age group of 15-30 years are 26.9 percentage point more likely to migrate than children. Similarly, population aged 30 years or higher are 40.7 percentage point more likely to migrate than children. Both results are measured at 28.19 years and are significant at $1 \%$ level. Similarly, being a male is associated with 30.8 percentage point decrease in the probability of moving into a place. The result is significant at $1 \%$ level.

Household size also exhibited negative relationship with the likelihood of rural migration. A unit increase the household size is associated with 0.6 percentage point decrease in the probability of rural in-migration, measured at 6.15 members. This result is significant at 1\% level. However, the relationship between the recentness of migration and the likelihood of moving into a place in rural area was not statistically significant. However, the geographical and administrative region does seem to significantly influence people's decision to move to a place. The relationships between the perceptions of people towards the facilities they use and their migration decision was statistically insignificant.

\section{Results for Regions}

The correlations for the relationships between migration and living in different administrative regions are mixed. Living in Eastern region is associated with 8.2 percentage point increase in the probability of migration, whereas living in the Central region is associated with 5.9 percentage point increase in the probability of migration. Similarly, living in the Western and the Far-Western regions are associated with 7.6 and 10.1 percentage point increase in the probability of migration. All of these results are compared against the probability of migration in the Mountain region. These results are significant at $1 \%$ level.

In contrast, we found that the relationship between living in the Mid-Western region and the probability of migration is not statistically significant. This was not the case for geographical regions though we found that living in Terai is associated with 12.2 percentage point increase in the probability of migration. This result is significant at $1 \%$ level.

\section{Findings and the CRSP}

Two of the main arguments for establishing CRSP are that it is the poor people who migrate, and they migrate in search of access to basic services. The findings in this chapter suggest that these arguments are either not as strong as claimed in the CRSP or are contrary to the dynamics on ground. If we just look at people's migration decision and the availability of basic services at a place, we find that the relationship is statistically insignificant once we control for the variations in the geographical and administrative regions. This suggests that we cannot make a causal claim that people are primarily considering the availability of basic facilities when they decide to migrate. We can conclude that in the least, the arguments put forth in the CRSP need further examination before the policy is put into practice.

Another finding in the chapter that contrasted with the arguments in the CRSP is related to the socio-economic status of people. The policy paper claims that it is the low quality of life in rural Nepal that propels the rural out-migration. If this were true, then we should expect to find that people belonging to lower socio-economic strata should migrate more than those belonging to a higher socio-economic strata. However, we 
find that people with higher socio-economic status, as measured by their expenditures on food consumption are more likely to migrate than those with lower socio-economic status. This means that the richer the people are in rural Nepal, the more likely they are to migrate.

We also identified few other factors that had major influence in people's migration decision. Sex, household size, and the region of residence have significant impact in people's migration decisions. This suggests that perhaps gender roles in Nepalese society plays a major impact in migration decision than the access to basic services. This is something worthwhile while making policies for resettlement. Unfortunately, the CRSP does not consider the role of gender and its impact on migration in its argument for compact settlements in rural Nepal.

Household size is another factor that the CRSP does not include in its discussion. The findings regarding the relationship between household size and an individual's migration decision contrasted with the hypothesis I presented earlier. The analysis found that people from larger households are less likely to migrate than people from smaller households. There are few reasons as to why this might be happening in Nepal. Members in large households might contribute more non-financially to the household than those who belong to a small household. For instance, an elder child in a large household might be expected to take care of his siblings. His likelihood to migrate, thus, reduces as the number of siblings increase because he needs to take care of them.

This finding might be explained with the new economics of labor migration theory. The theory states that households, and sometimes communities, use migration to mitigate risks, and maximize income and status (Massey, 1999). As the household size and gender roles are also shown to influence people's migration decision (Shrestha and Bhandari, 2007), it might be that the need for labor for agricultural purposes might hold people from larger family from migrating.

This might be problematic while establishing CRS in Nepal because CRS would require that people live near each other. For a larger household, this would either mean less space per household member or the need to switch to nuclear families, which is not the usual family structures in rural Nepal. As living in crammed spaces might mean unhygienic conditions for family members, it does not seem an attractive option to reduce the per capita space available for living for an individual. The other option, which would entail having separate households is usually not practiced in rural Nepal. It is common for males to stay with their parents even after they are married. Children are generally expected to take care of their parents. Thus, asking people to live in separate households is not realistic in rural Nepal.

One possible argument against this could be that cultural norms are dynamic, i.e. they keep on evolving through complex mechanisms in society. If it benefits the society at large, then perhaps the government should intervene and redefine the cultural norms. In the case of CRS, the argument could be something that if people are going to have better quality of life at the end, perhaps the government should intervene and redefine cultural norms. While redefining cultural norms might not be problematic in itself, it is problematic to do so on the assumption that the people would want the type of norms imposed by the government bureaucrats on multiple accounts.

The evidence suggests that the major factors that influence people's decision to migrate are not as suggested in the CRSP. This leads us to infer that the diagnosis of the dynamics by the policymakers is not always representative of the situations on ground. I used the term "representative" rather than "accurate" here because given the diversity of Nepal, it might be difficult to form an accurate picture of what is happening in each nooks and corners of the country. Changing cultural norms for the sake of productivity if done abruptly can be counter-productive as we have seen in the case of disasters related to compact settlements in Tanzania, which will be discussed in another chapter later on.

This brings us to the findings from the analysis that contrasts with the claims in the CRSP. We find that in Nepal the marginal effects on the relationship between living in different regions and the probability of migration are significant. For instance, those living in Terai are more likely to have migrated there than those living in the hills. In other words, those living in the mountains are far less likely to have migrated there from other districts in the Mountain or from Hills, and Terai.

For instance, to make the argument for CRS more concrete, one can point out the enrollment status in the schools in different regions. The left-hand chart in Figure 2 shows us that a 
primary school in the Terai has more than double the number of students than a school in the Mountain. One might argue that given the scattered settlements in the Mountain and fewer students enrollment, it makes sense to move forward with the compact settlements that ensures provision of facilities in a cost-

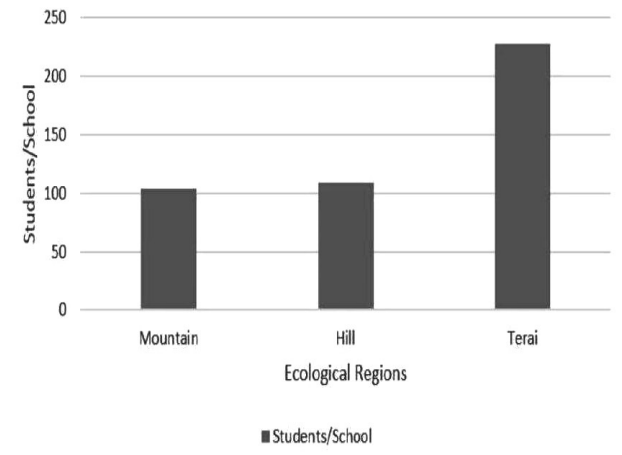

effective way. In the right-hand chart in Fig. 2, we can observe that the Terai and the Hills have four times as many primary schools per square kilometer than the Mountain region. Thus, the student enrollment and the density of schools do seem to point towards both the lack of facility and less use of them in rural Mountain areas.

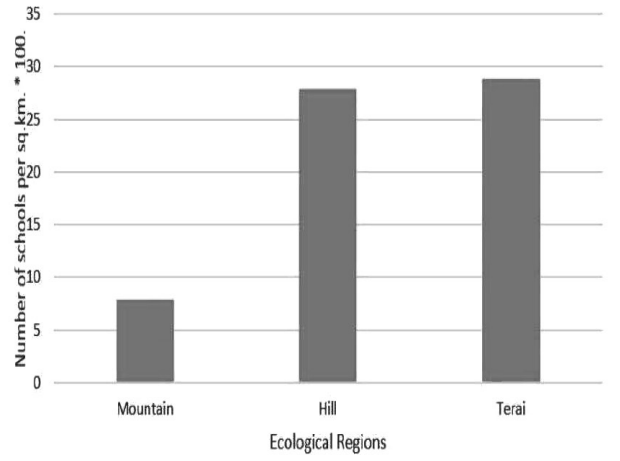

Fig 2: Data from CBS(2012) and DoE(2012).

However, this should not lead us to claim that the people would migrate to the Mountain region if facilities are established. Two findings from our analysis support this claim. First, we found that an average person in Nepal is more likely to move into a district in Terai region compared to the Mountains and Hills. Moreover, we also found that the time taken to facilities is not a significant predictor of people's migration decisions. Thus, claiming that having more schools would lead to more enrollment and more migration is unfounded at best.

Another aspect of the results related to the compact settlements is the perception of the existing facilities. We found that perception of the adequacy of basic service facilities is not a crucial factor in influencing people's migration decision. For instance, it might be because people in rural Nepal look into other factors more than the availability of basic services. As majority of the people in the rural places are farmers, people might look at the irrigation facilities and the productivity of the land more while migrating. Similarly, social ties might also play a role in the migration, which we could not measure through the NLSS data.

It could also be that people might not be expecting too much out of basic facilities such as a health post or a primary school given the sub-standard quality of services these facilities provide. Thus people with low expectations might be relatively content with the facilities they get as they might not have had access to better basic facilities to compare their experiences with. If this was the case, the perception of basic service facilities would not influence people's migration decision significantly. This is important to note because we would expect that more discontent people are with the services, the more likely they would seek other services keeping all other things constant.

One other reason could be that it is the poor people who are usually discontent with the services that are available to them. Poor people have limited means to provide themselves with resources as people from higher socio-economic status do. As a result, poor people might be limited to using facilities that have minimal costs. These kinds of facilities usually tend to be public facilities in Nepal as they are subsidized by the government. The rich people on the other hand, might be using private health service facilities. While the poor are discontent, they are left with few options whereas the rich can perhaps afford facilities that cost more. This aligns with the finding that the poor people are also less likely 
to migrate than the rich people. If this were the case, the important driver for migration would not be whether people live closer to facilities but if they can use the type of facilities they need, which depends on their socio-economic status.

\section{Conclusion}

To conclude, we analyzed migration patterns in different regions of Nepal to test the claims in the CRSP. Understanding the migration patterns also helped us identify the prominent factors that result in migration. As CRS would mean resettlement of people, identifying these factors would help us better design effective interventions.

We noted that distance to services does not significantly impact migration decision of people. We also found that people from lower socio-economic status are less likely to migrate in Nepal than people from higher socio-economic status. The latter finding contrasts with the arguments for CRS in Nepal. We also observed that age, sex, household size and the regions people live in are stronger predictors of people's migration decision than access to facilities.

Sex was one of the most prominent factors that determined migration behavior. Being a male is associated with around 31 percentage point increase in the probability of migration than being a female when controlled for distance to a primary school and other factors. Similarly, we noted that generally younger people between the age bracket of 15 and 30 migrate more in rural Nepal. Finally, the analysis suggested that the perception of facilities people use does not have a statistically significant impact in people's migration decision.
These findings suggest that rather than focusing on providing more services, it might be more cost effective to focus on improving the quality of services provided, reducing gender gap and providing economic opportunities for younger people if the state is concerned with improving the quality of life for Nepali people. This is because we saw that the factors such as age and sex are more important predictors than the distance people need to travel to get access to services when people choose whether or not to migrate.

Similarly, the large differences in the migration patterns in different regions suggest that perhaps development activities in future be conducted on a more proportional level to include different parts of the country. Having CRS would mean concentrating development activities in a small locality neglecting other areas because CRS are by their nature resource intensive. It would be a mighty task, if not impossible and counterintuitive, for a developing country like Nepal to spend its resources both on developing CRS and helping people in marginalized places get access to basic services at the same time while also addressing the issues relating to gender inequality and youth unemployment.

For now, it suffices to suggest that CRS might not be the ultimate solution as claimed in the CRS policy paper to improve the low quality of life for the majority of the people in rural Nepal. Focusing on issues relating to quality of public services, gender inequality, lack of opportunities for youth and regional disparities in development activities will perhaps be more cost effective for the state than venture out in developing CRS, which might use valuable state resources to perpetuate the cycle of low quality of life even more profoundly.

\section{References}

Bilsborrow, R.E., (ed.) (1998). Migration, urbanization, and development: new directions and issues. United National Population Fund, New York: Springer Science \& Business Media.

Bohra-Mishra, P. \& Douglas S. M. (2011). Individual decisions to migrate during civil conflict." Demography 48 (2), 401-424.

Central Bureau of Statistics (2012), National population and housing census 2011. National Report. Retrieved from http://cbs.gov.np/image/data/Population/National\%20Report/National\%20Report. pdf

Department of Education (DoE) (2012). School level educational statistics of Nepal: Consolidated report 2011. Ministry of Education, Government of Nepal. Retrieved from http://www.ncf.org.np/ upload/files/1007_en_Consolidated\%20Report\%202068\%20(\%202011)_1346397795.pdf 
Ezra, M., \& Gebre-Egziabher K. (2001). Rural out-migration in the drought prone areas of Ethiopia: a multilevel analysis. The International Migration Review: 35 (3), 749-771.

Fentiman, A., Hall, A. \& Bundy, D. (1999). School enrolment patterns in rural Ghana: a comparative study of the impact of location, gender, age and health on children's access to basic schooling. Comparative education, 35 (3), 331-349.

Gray, C. L. (2009), Environment, land, and rural out-migration in the southern Ecuadorian Andes." World Development, 37 (2), 457-468.

Gurung, H., KC, B.K., Shrestha, C.B., Mishra, C.,Ojha, D.P.,Timilsina, P.P.,Gurung, S.B.\& Kansakar, V.B.S. (1983). Internal and International Migration in Nepal. Kathmandu: National Commission on Population.

Lloyd, C.B., Mete, C. \& Sathar, Z.A. (2005). The effect of gender differences in primary school access, type, and quality on the decision to enroll in rural Pakistan. Economic Development and Cultural Change. 53 (3), 685-710.

Massey, D. S. (1999). Why does immigration occur? A theoretical synthesis. In C. Hirschman, P. Kasinitz, \& J. DeWind (Eds.), The handbook of international migration: The American experience. Pp. 34-52. New York: Russell Sage Foundation.

Nawrotzki, R.J., Riosmena, F. and Hunter, L.M. (2013). Do rainfall deficits predict US-bound migration from rural Mexico? Evidence from the Mexican census." Population research and policy review, 32(1),129-158.

National Planning Commission (2013). Policy brief. Government of Nepal with support from UNHabitat in Nepal. Compact Rural Settlements Development Strategy for Nepal:

Sharma, S. K., Sawangdee, Y., \& Sirirassamee, B. (2007), Access to health: women's status and utilization of maternal health services in Nepal. Journal of biosocial science, 39 (5), 671-692.

Seddon, D., Adhikari, J., \& Gurung, G. (2002), Foreign labor migration and the remittance economy of Nepal. Critical Asian Studies, 34 (1), 19-40.

Sen, A. (2005), Human rights and capabilities. Journal of human development 6 (2), 151-166.

Shrestha, S.S. \& Bhandari, P. (2007). Environmental security and labor migration in Nepal. Population and Environment 29 (1), 25-38

Thapa, R. B. \& Murayama, Y. (2010), Drivers of urban growth in the Kathmandu Valley, Nepal: Examining the efficacy of the analytic hierarchy process. Applied Geography, 30 (1), 70-83.

White, M.J. \& Lindstrom, D.P. (2005), Internal migration. US: Springer 